\title{
Ist Schnäuzen gut geeignet um die Nasenhöhle zu säubern?
}

\author{
Eine Frage, die sich Viele schon einmal gestellt haben...
}

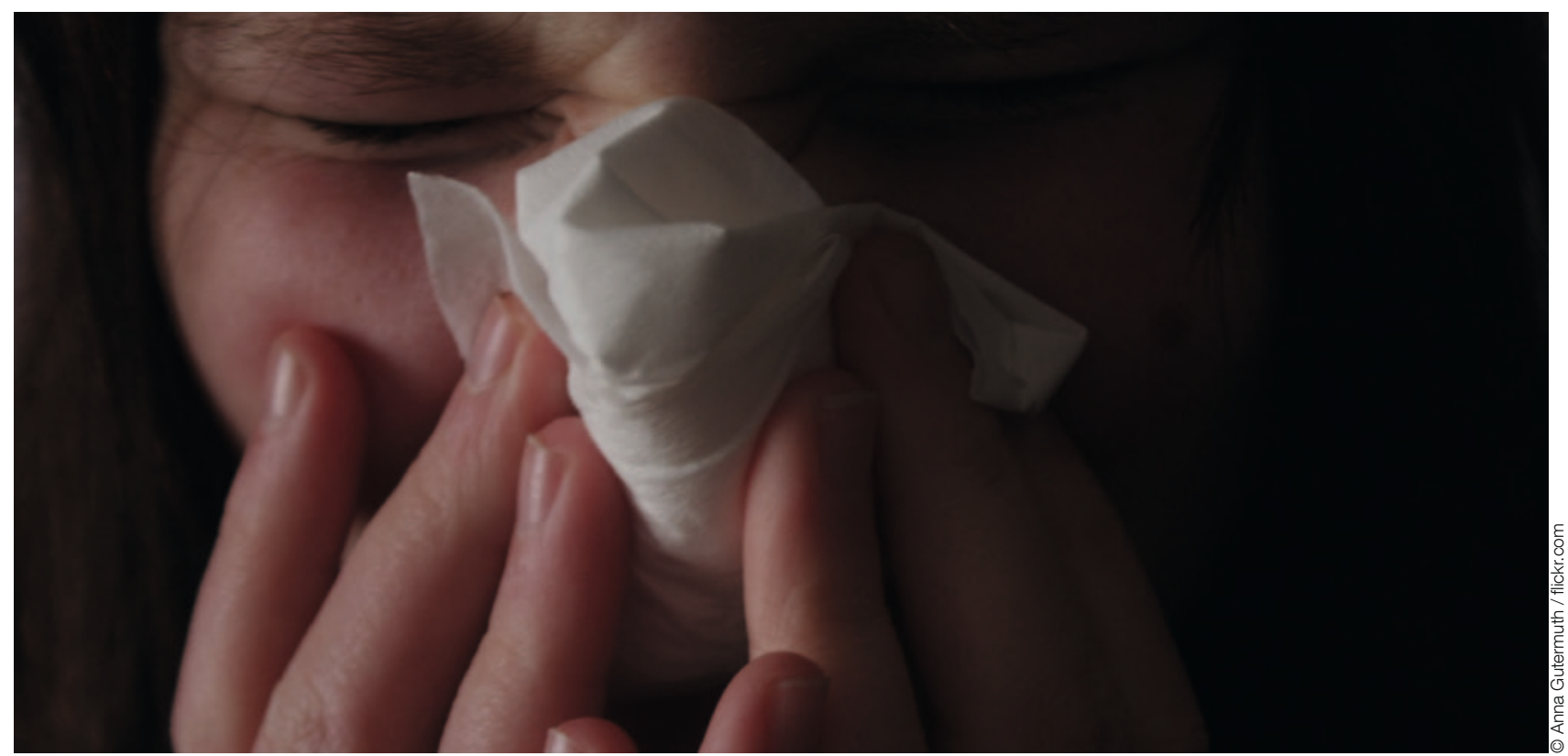

kräftiges Schnäuzen...

Beim Schnäuzvorgang wird in der Exspiration bei verschlossenem Mund und Nase ein Überdruck in der Nase erzeugt, der sich nach Öffnung der Nase rasch abbaut und somit Sekret nach außen befördert. Allerdings kann der nasale Überdruck auch pathologisches Sekret bei viraler oder bakterieller Entzündung in die Nasennebenhöhlen oder gar ins Mittelohr drücken. Letzteres geschieht insbesondere bei Kindern, deren Eustachische Röhre (Tuba auditiva Eustachii) kurz und gerade ist.

\section{Zur Person}

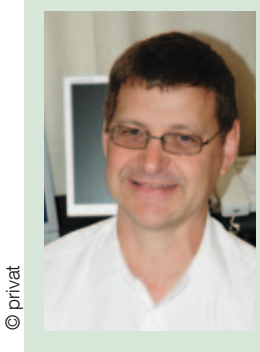

Ao. Univ.-Prof. Dr. Matthäus Ch. GrasI

ist als Facharzt für Hals- Nasen-Ohrenheilkunde an der HNO-

Univ. Klinik der Medizinischen Universität Wien tätig. Außeror-

dentlicher Universitätsprofessor mit Schwerpunkt in der

medizinischen Lehre. Master of Medical Education (Heidelberg).
Nasenloch zuzuhalten unter geringem Druck ausgeschnäuzt werden. Alternativ kann dazu ein durch „Aufziehen“ entstehender Unterdruck in der Nase und im Nasenrachenraum das vorhandene Sekret nach kaudal befördern. Dieses wird meist geschluckt und die Keime letztendlich im Magen unschädlich gemacht, die ansonsten im Taschentuch landen und oft über Handkontakt weitergegeben werden. Durch exzessives „Aufziehen“ kann bei Kindern jedoch ein chronischer Unterdruck entstehen, der wiederum zu einem Paukenerguss im Mittelohr führen kann.

Bei blutigem Nasensekret ist Schnäuzen kontraproduktiv, da die Blutung verstärkt wird und es zudem meist zu einer Verschmutzung der Kleidung kommt.

Krusten sind durch Schnäuzen kaum entfernbar. Hier fördert der Einsatz von Ölen oder Salben die Gleitfähigkeit und erst dann können sie durch vorsichtiges Schnäuzen entfernt werden. Keinesfalls sollen Krusten mit den Fingern oder Wattestäbchen mobilisiert werden, da dies oft zu Schleimhautblutungen führt. 